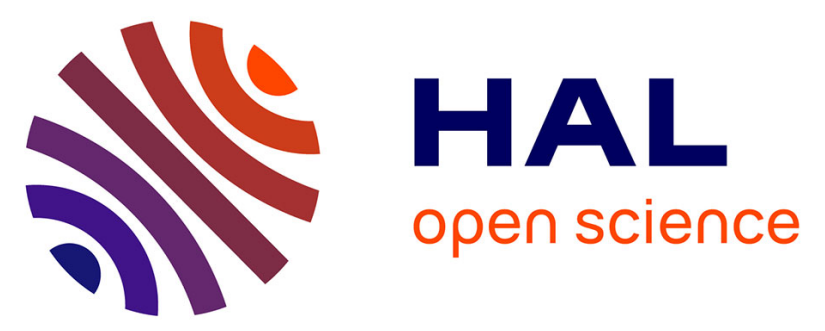

\title{
Enantio- and Substrate-Selective Recognition of Chiral Neurotransmitters with C 3 -Symmetric Switchable Receptors
}

\author{
Jian Yang, Bastien Chatelet, Véronique Dufaud, Damien Hérault, Marion \\ Jean, Nicolas Vanthuyne, Jean-Christophe Mulatier, Delphine Pitrat, Laure \\ Guy, Jean-Pierre Dutasta, et al.
}

\section{To cite this version:}

Jian Yang, Bastien Chatelet, Véronique Dufaud, Damien Hérault, Marion Jean, et al.. Enantioand Substrate-Selective Recognition of Chiral Neurotransmitters with C 3 -Symmetric Switchable Receptors. Organic Letters, 2020, 22 (3), pp.891-895. 10.1021/acs.orglett.9b04440 . hal-02611848

\author{
HAL Id: hal-02611848 \\ https://hal.science/hal-02611848
}

Submitted on 23 Mar 2021

HAL is a multi-disciplinary open access archive for the deposit and dissemination of scientific research documents, whether they are published or not. The documents may come from teaching and research institutions in France or abroad, or from public or private research centers.
L'archive ouverte pluridisciplinaire HAL, est destinée au dépôt et à la diffusion de documents scientifiques de niveau recherche, publiés ou non, émanant des établissements d'enseignement et de recherche français ou étrangers, des laboratoires publics ou privés. 


\title{
Enantio- and Substrate-Selective Recognition of Chiral Neurotransmitters with $C_{3}$-Symmetric Switchable Receptors
}

\author{
Jian Yang, Bastien Chatelet, Véronique Dufaud, Damien Hérault, Marion Jean, Nicolas Vanthuyne,
} Jean-Christophe Mulatier, Delphine Pitrat, Laure Guy, Jean-Pierre Dutasta, and Alexandre Martinez*

ABSTRACT: We report on the synthesis of $C_{3}$-symmetric enantiopure cage molecules 1, which exhibit remarkable to exclusive enantioselective recognition properties toward chiral ammonium neurotransmitters. Strong changes in the substrate selectivity are also observed when different stereoisomers of $\mathbf{1}$ are used. Furthermore, protonation/deprotonation induces a reversible modification of the conformation of $\mathbf{1}$, which switches from an imploded to an inflated form, leading to ejection and reuptake of the guest initially encaged inside the cavity.

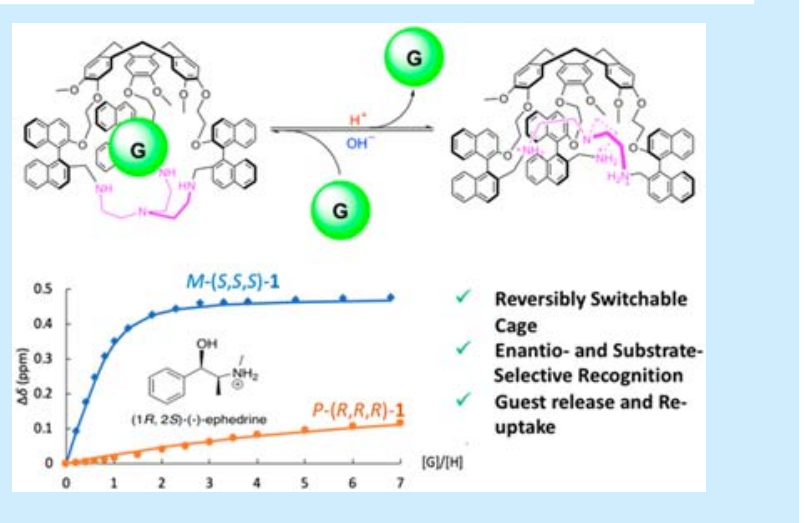

$\mathrm{C}$ hiral recognition plays a crucial role in living systems and is also a key issue for researchers dealing with chiral separations or asymmetric catalysis. If chiral receptors and catalysts found in Nature display complex structures devoid of symmetry, their synthetic counterparts present frequently symmetry properties, like rotational axes. ${ }^{1}$ Besides the beauty of symmetrical molecules, considerations of symmetry allow simplifying both the synthesis and the analysis and may improve the selectivity in enantioselective recognition or catalysis by reducing the number of diastereomeric host-guest complexes or transition states. ${ }^{2}$ However, to perform chiral recognition, receptors or catalysts have to belong to the point groups $C_{\mathrm{n}}$ (including $C_{1}$ ) or $D_{n} \cdot{ }^{3}$ Since the seminal work of Kagan highlighting the advantages of $C_{2}$-symmetric ligands in asymmetric catalysis, numerous chiral ligands and receptors with 2 -fold rotational symmetry have been reported. ${ }^{4,5}$ In contrast, molecules with 3 -fold rotational symmetry capable of chiral recognition remain rare. ${ }^{6}$ The ability of $C_{3}$ symmetric hosts to discriminate enantiomers of ammoniums was even the subject of scientific controversy. ${ }^{1 \mathrm{a}, 6}$ However, the experimental work of Ahn et al. and then the studies reported by Hauberhauer et al. followed by the rationalization of Moberg put an end to this debate. ${ }^{1 a, 7,8}$ However, very few $C_{3^{-}}$ symmetric hosts capable of chiral recognition of ammoniums have been reported to date, and the best selectivity reached only a modest value of 8.4 (87:13 ratio). ${ }^{7,8}$ Therefore, experimental evidence that receptors with a 3 -fold rotational symmetry are able to recognize ammoniums with enantioselectivity as high as those with 2 -fold rotational symmetry remains to be brought.
Furthermore, as chiral ammoniums play a crucial role in biological systems, for instance, as neurotransmitters, there is also a challenge to build a receptor capable of displaying high substrate selectivity in favor of one neurotransmitter, because of its potential applications, in sensing or detection. ${ }^{9}$ Moreover, if such a receptor is able to control the uptake and release of the guest by switching between two strongly different states upon the action of an external stimulus, this could offer new ways for drug delivery. ${ }^{10}$

Here, we report on the synthesis of $C_{3}$-symmetric molecular cages that display unprecedented enantioselective recognition properties for chiral ammoniums of biological interest. Binding constants up to $10^{5} \mathrm{M}^{-1}$ can be reached by receptor $M-(S, S, S)$ 1 , whereas low $\left(100 \mathrm{M}^{-1}\right)$ to no binding was observed with its enantiomer $P-(R, R, R)-1$. Changing the stereochemistry of the receptor also induced strong changes in the substrate selectivity: receptor $M-(S, S, S)-1$ bound ephedrine more strongly than adrenaline, whereas the opposite trend was observed for its enantiomer $P-(R, R, R)-\mathbf{1}$. Moreover, this cage could be reversibly switched from an inflated form to an imploded one upon protonation/deprotonation, allowing for an easy control of the uptake and release of the enantiomerically pure neurotransmitters. 


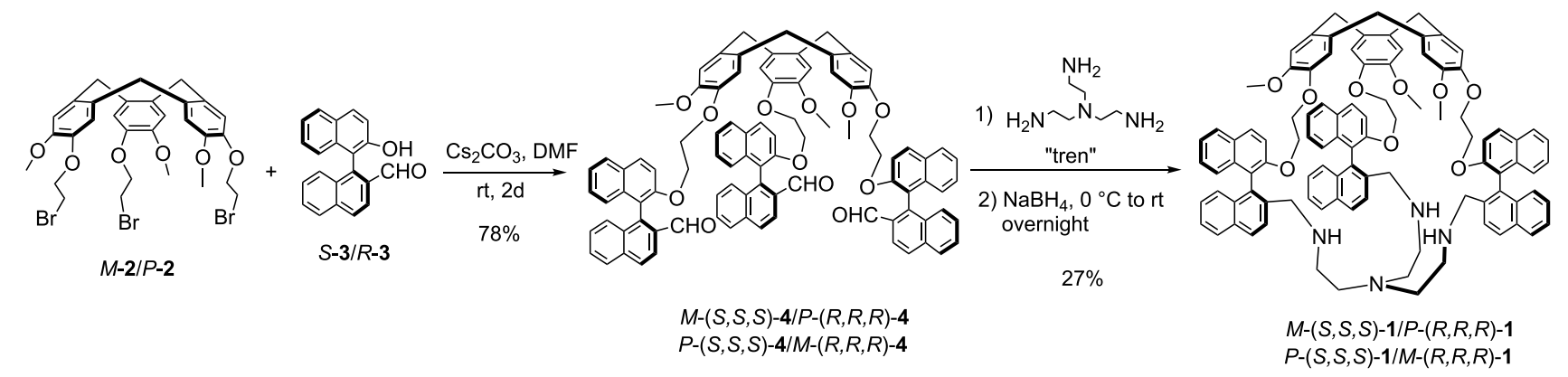

Scheme 1 shows the synthetic route followed to obtain the four $C_{3}$-symmetric stereoisomers of cage 1 . Cyclotriveratrylene (CTV) 2 was obtained enantiomerically pure according to our previously reported procedure. ${ }^{11,12}$ Racemic 2 '-hydroxy-[1,1'binaphthalene]-2-carboxaldehyde derivative 3 was synthesized using the methodology described by Xie et al., ${ }^{13}$ and a subsequent resolution with a chiral HPLC afforded the enantiopure compound $(S)-3$ and $(R)-3$ (Figures S1-S3). Their absolute configuration was then assigned using ECD spectroscopy (Figures S4 and S5). Then, M-2 or P-2 was reacted with $(S)-3$ or $(R)-3$ in DMF using $\mathrm{CsCO}_{3}$ as a base to yield enantiomerically and diastereomerically pure $P-(S, S, S)-4$, $P-(R, R, R)-4, M-(S, S, S)-4$, and $M-(R, R, R)-4$. Finally, a reductive amination gave the expected hemicryptophane cages $P-(S, S, S)$ 1, $P-(R, R, R)-1, M-(S, S, S)-1$, and $M-(R, R, R)-1$ in $27 \%$ yield as single isomer in each case. ${ }^{14}$ The NMR spectra indicate that all the stereoisomers of cage 1 display, on average, a $C_{3}$ symmetry in solution (Figures S14 and S19).

Crystals of $P-(R, R, R)-1$ suitable for X-ray diffraction analysis were obtained by slow evaporation from a concentrated solution of the cage in $\mathrm{CHCl}_{3} / \mathrm{CH}_{3} \mathrm{OH}$. Because of traces of $\mathrm{HCl}$ in $\mathrm{CHCl}_{3}$, the $P-(R, R, R)-1$ compound crystallized as its protonated counterpart $P-(R, R, R)-1-3 \mathrm{H}^{3+}$ with protonation on each secondary amine (Figure 1$)$. Interestingly, this triproto-
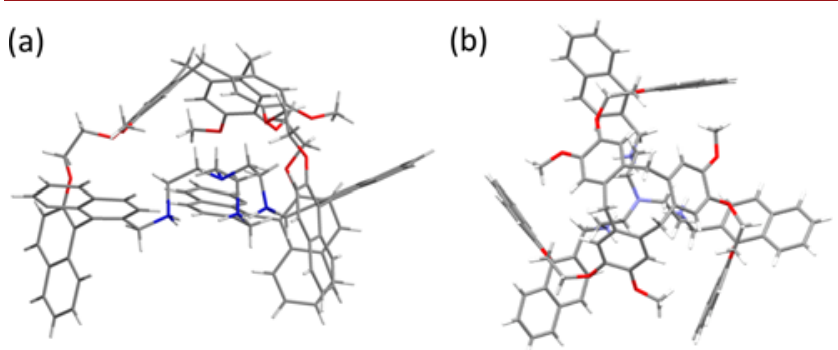

Figure 1. X-ray structure of $P-(R R R)-1 \cdot 3 \mathrm{H}^{+}$: (a) side view and (b) top view.

nated structure exhibits a $C_{3}$ symmetry but with an unexpected imploded conformation: the tren (tris(2-aminoethyl)amine) moiety appears fully collapsed inward the CTV unit, leading to a compound devoid of cavity. $\mathrm{C}-\mathrm{H} \cdots \mathrm{O}$ and $\mathrm{C}-\mathrm{H} \cdots \pi$ interactions between the $\mathrm{NCH}_{2} \mathrm{CH}_{2}$ protons of the tren unit and both the oxygen atoms and aromatic rings of the CTV could account for the stability of this imploded state $(\mathrm{C}-\mathrm{H} \cdots \mathrm{O}$ and $\mathrm{C}-\mathrm{H} \cdots \pi_{\mathrm{Ar}}$ distances of 2.94 and $3.03 \AA$, respectively). The ${ }^{1} \mathrm{H}$ NMR spectrum of this protonated form was obtained either by dissolution of these crystals in $\mathrm{CDCl}_{3}$ or by addition of 3 equiv of picric acid to compound $P-(R, R, R)-1$ (Figures $S 6$ and $S 25)$. One can see that, despite the protonation of the amines, one signal of the $\mathrm{NCH}_{2}$ protons is strongly high-field shifted when compared to the same protons in the deprotonated $P$ $(R, R, R)-1$ cage (from $1.05 \mathrm{ppm}$ (deprotonated) to $-0.26 \mathrm{ppm}$ (protonated), Figure 2$)$ ). This is consistent with the imploded

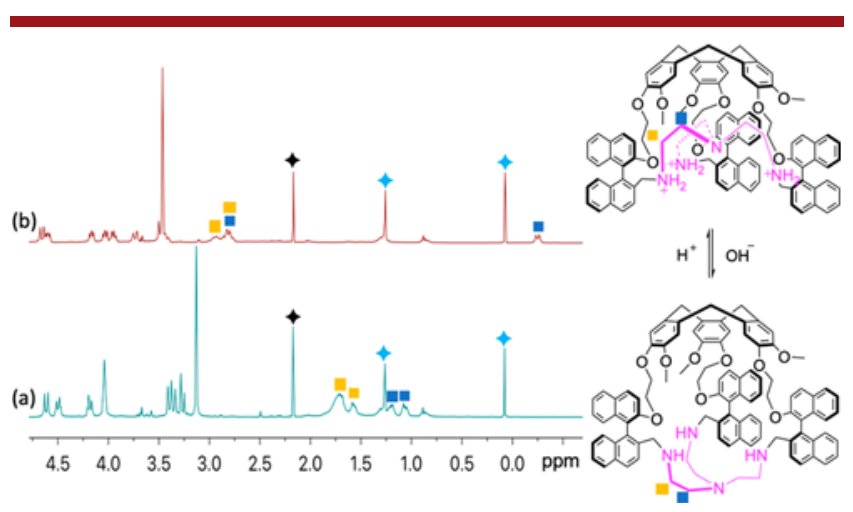

Figure 2. ${ }^{1} \mathrm{H}$ NMR $\left(\mathrm{CDCl}_{3}, 400 \mathrm{MHz}, 298 \mathrm{~K}\right)$ spectra of (a) $P$ $(R, R, R)-\mathbf{1}$ and $(\mathrm{b}) P-(R, R, R)-\mathbf{1} \cdot 3 \mathrm{H}^{3+}$. The black and blue $\boldsymbol{r}$ represent acetone and grease, respectively.

conformation of the protonated compound observed in the solid state, where one of the diastereotopic protons of the $\mathrm{NCH}_{2}$ units appears in the shielding area of the CTV moiety. Furthermore, cross-peaks between the protons of the $\mathrm{NCH}_{2}$ of the tren moiety and those of the aromatic rings of the CTV core were evidenced on the NOESY map (Figure S30) indicating short distances between the two units. On the contrary, when the similar NOESY experiment was performed on the deprotonated cage, no NOE correlation between the tren moiety and the CTV unit was shown, suggesting a welldefined cavity in the cage compound $P-(R, R, R)-1$ (Figure S23). More insight into this strong difference in the conformation of $P-(R, R, R)-1$ and $P-(R, R, R)-1 \cdot 3 \mathrm{H}^{3+}$ is further given by the ability of $P-(R, R, R)-1$ to complex tetramethylammonium $\left(\mathrm{Me}_{4} \mathrm{~N}^{+}\right)$ with a binding constant of $373 \mathrm{M}^{-1}$, whereas no complexation could be detected with its protonated counterpart $P-(R, R, R)-\mathbf{1}$. $3 \mathrm{H}^{3+} \cdot{ }^{15}$ All these NMR experiments strongly support that the imploded conformation of $P-(R, R, R)-1 \cdot 3 \mathrm{H}^{3+}$ is maintained in solution whereas its basic partner $P-(R, R, R)-1$ presents a hollow core. As $\mathrm{pH}$ switch can be used as a specific stimulus to perform reversible nanomechanical processes at molecular level, ${ }^{16}$ we then investigated whether the protonation/ deprotonation of cage 1 could enable the control of the dynamic motion from an inflated state to a fully imploded one. We were pleased to note that the alternating use of $\mathrm{HCl}$ (aq) and $\mathrm{NaOH}$ (aq) resulted in a reversible switch from a fully inflated form to a collapsed one and that at least five cycles could be performed between these two states (Figure S7). 
Thus, the $\mathrm{pH}$ acts as an effective and simple stimulus to switch 1 reversibly from a collapsed state to a reinflated cage.

Once the conformational issues of the deprotonated and protonated cages 1 were solved, we examined the ability of the four inflated $C_{3}$-symmetric receptors $P-(S, S, S)-\mathbf{1}, P-(R, R, R)-\mathbf{1}$, $M-(S, S, S)-1$, and $M-(R, R, R)-1$ to complex chiral ammonium neurotransmitters: $(1 R, 2 S)-(-)$-ephedrine, $(1 R, 2 S)-(-)$-norephedrine, $(1 S, 2 S)-(+)$-pseudoephedrine, and L-adrenaline. ${ }^{1} \mathrm{H}$ NMR titration experiments were performed, and the modeling of the resulting titration curves gives rise to the binding constants given in Table 1. In most of the cases, the best fit was

Table 1. Association Constants of the Enantiopure Receptors 1 with Ammonium Guests in $\mathrm{CDCl}_{3} / \mathrm{CD}_{3} \mathrm{OD}$ 95/ 5 at $298 \mathrm{~K}$

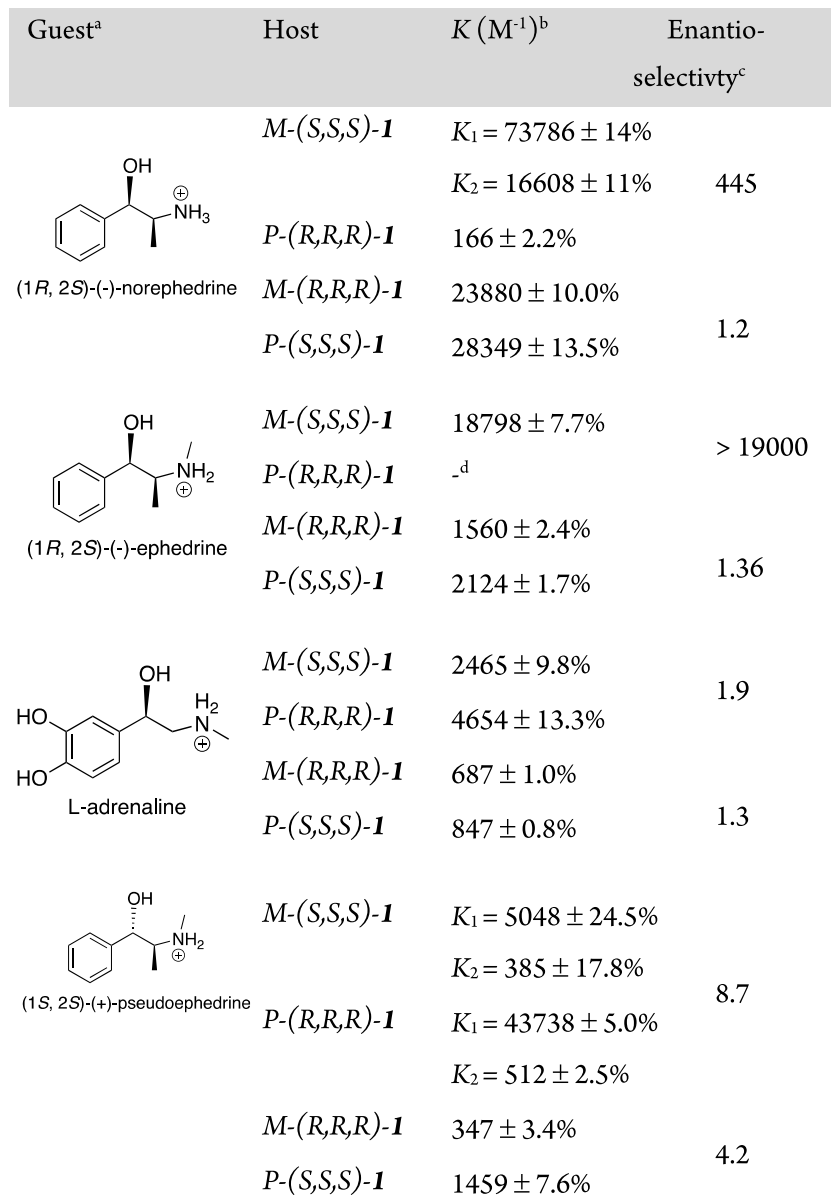

${ }^{a}$ Picrate was used as counterion. ${ }^{b} K$ values were determined by fitting the ${ }^{1} \mathrm{H}$ NMR titration curves of proton of the guest using Bindfit, the error bars arise from the fitting. ${ }^{18}{ }^{c}$ Defined as $K_{\text {(one enantiomer) }}$ / $K_{\text {(other enantiomer). }}{ }^{17}{ }^{d}$ No complexation was observed.

achieved with a 1:1 host/guest stoichiometry, except for (i) norephedrine guest and $M-(S, S, S)-1$ host and (ii) pseudoephedrine guest and $M-(S, S, S)-1$ and $P-(R, R, R)-1$ hosts where two complexes were formed subsequently with a $1: 1$ and then a $1: 2$ host/guest ratio. The two enantiomeric hosts $M-(R, R, R)-1$ and $P$ - $(S, S, S)-1$ displayed good substrate selectivities with $K_{\text {ephedrine }} /$ $K_{\text {adrenaline }}$ of 2.3 and 2.5 and with $K_{\text {norephedrine }} / K_{\text {adrenaline }}$ of 34.8 and 33.5, respectively. ${ }^{17}$ However, when complexed with tested guests, only low enantioselectivities were achieved, the best result being obtained with pseudoephedrine, with a modest enantioselectivity $K_{P-(S, S, S)-1} / K_{M-(R, R, R)-1}$ of 4.2 . In contrast, the two other enantiomeric cages $M-(S, S, S)-1$ and $P-(R, R, R)-1$ exhibited unprecedented enantioselectivity as $C_{3^{-}}$ symmetric receptors: with the primary ammonium norephedrine, an enantioselectivity value $\left(K_{M-(S, S S S)-1} / K_{P-(R, R, R)-1}\right)$ of 445 was measured and with the secondary ammonium ephedrine an exclusive enantioselectivity was observed with a binding constant close to $19000 \mathrm{M}^{-1}$ for the $M-(S, S, S)-1$ host, while no binding occurred with its enantiomer counterpart $P$ $(R, R, R)-1$.

The ${ }^{1} \mathrm{H}$ NMR titration curves shown in Figure 3 clearly evidence the difference in the binding properties of these two

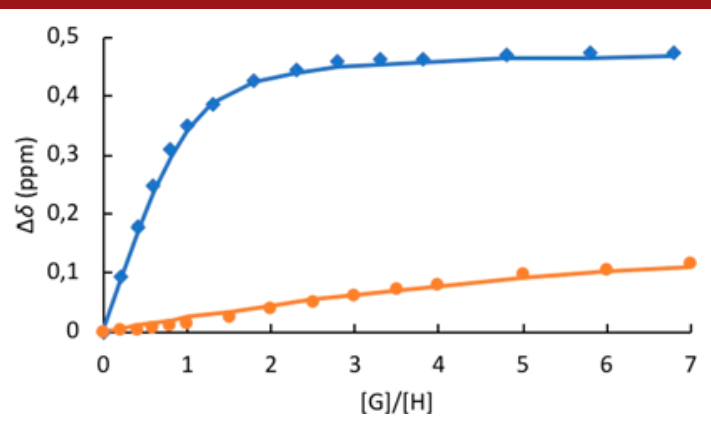

Figure 3. Titration curves of hosts $M-(S, S, S)-1$ (blue) and $P-(R, R, R)$ 1 (orange) with $(1 R, 2 S)-(-)$-ephedrine. The complexation-induced shifts $\left(\Delta \delta=\delta_{\text {uncomplex }}-\delta_{\text {complex }}\right)$ of the guest's proton at $5.18 \mathrm{ppm}$ were recorded and plotted as a function of the ratio $[\mathrm{G}] /[\mathrm{H}]$ (dots). Curves were fitted with the Bindfit program (solid lines).

enantiomers toward ephedrine. Changing only one stereogenic center in the guest structure, i.e., switching from ephedrine to pseudoephedrine, led to complete reverse of the enantioselectivity: an enantioselectivity of 8.2 in favor of $P-(R, R, R)-\mathbf{1}$ was observed with pseudoephedrine as a guest. As a consequence, the host $P-(R, R, R)-1$ exhibits a strong substrate selectivity toward pseudoephedrine: a $K_{\text {pseudoephedrine }} / K_{\text {norephedrine }}$ ratio of 263 is reached and the substrate selectivity is even exclusive when pseudoephedrine is compared to ephedrine. Interestingly, the lower enantioselectivity obtained with L-adrenaline as substrate induced changes in substrate selectivities: the $M$ $(S, S, S)-1$ enantiomer preferentially binds norephedrine or ephedrine than adrenaline (with $K_{\text {norephedrine }} / K_{\text {adrenaline }}$ of 30 , and $K_{\text {ephedrine }} / K_{\text {adrenaline }}$ of 8 , respectively), whereas the enantiomer $P-(R, R, R)-1$ is adrenaline-selective with a selectivity $K_{\text {adrenaline }} / K_{\text {norephedrine }}$ of 28 and even exclusive when compared to ephedrine. Thus, switching from one enantiomer to another completely changed the substrate selectivity, allowing building selective receptors for a given neurotransmitter by simply using the mirror image of a cage.

As cage $P-(R, R, R)-1$ and obviously its enantiomer $M-(S, S, S)$ $\mathbf{1}$ are able to switch from a globular form to a fully imploded conformation upon an acidic stimulus (vide supra), we wondered if this nanoscale molecular motion could occur with a guest already encapsulated in the cavity, thereby expelling the included guest outside the cavity. Addition of picric acid to a solution of encapsulated ephedrine led immediately to the imploded structure of the cage $M-(S, S, S)$ 1 associated with the release of the ephedrine guest in the media (Figure 4). This result demonstrates that this molecular motion of the cage is possible despite the high stability of the initial host-guest complex $\left(K=19000 \mathrm{M}^{-1}\right)$. After subsequent addition of triethylamine, the host was reinflated and able to encage the ephedrine guest simultaneously, giving 
(e)
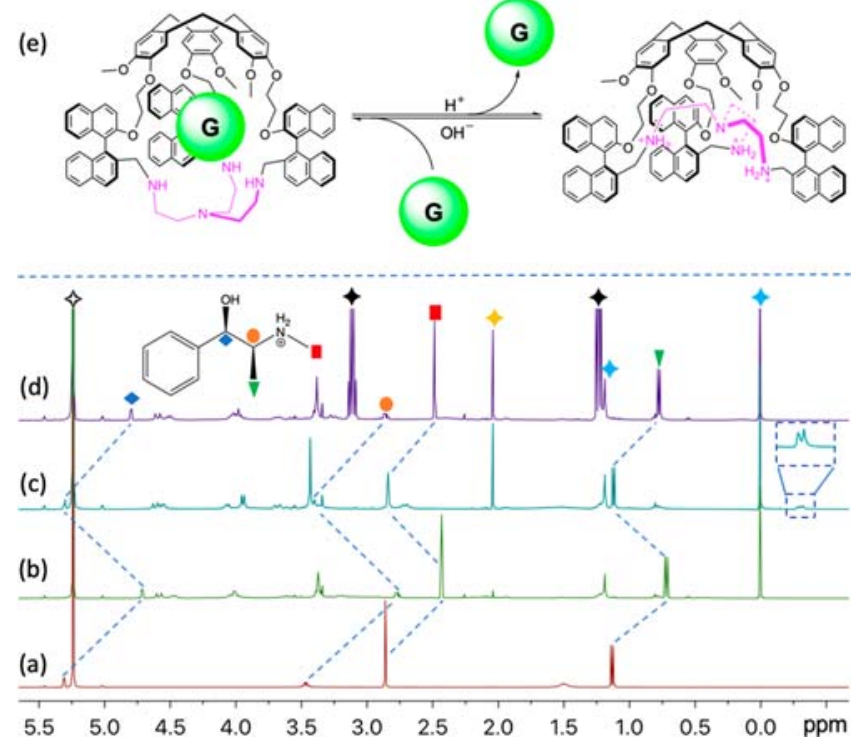

Figure 4. (a-d) ${ }^{1} \mathrm{H}$ NMR ( $\left.400 \mathrm{MHz}, \mathrm{CD}_{2} \mathrm{Cl}_{2}, 298 \mathrm{~K}\right)$ spectra of: (a) $(1 R, 2 S)-(-)$-ephedrine; (b) $(1 R, 2 S)-(-)$-ephedrine and equimolar of $M-(S, S, S)-\mathbf{1}$; (c) $(1 R, 2 S)-(-)$-ephedrine and equimolar of $M-(S, S, S)-\mathbf{1}$ and 3 equiv of picric acid, the peak at $-0.3 \mathrm{ppm}$ was zoomed to highlight the imploded conformation of $M-(S, S, S)-1$ after protonation; (d) $(1 R, 2 S)-(-)$-ephedrine and equimolar of $M-(S, S, S)-1$ and picric acid and excess of $\mathrm{Et}_{3} \mathrm{~N}$. (e) Schematic representation of reversible uptake and release of guest by $M-(S, S, S)-1$ upon protonation/deprotonation. White, black, yellow, and blue represent $\mathrm{CHDCl}_{2}, \mathrm{Et}_{3} \mathrm{~N}$, acetone, and grease, respectively.

back the initial host-guest complex. Thus, simple protonation/deprotonation induces a strong change of the conformation of the receptor allowing for the control of the reversible trap and release of the ephedrine neurotransmitter.

In summary, we have described the synthesis of four new $C_{3^{-}}$symmetric enantiopure cages and their enantioselective recognition toward chiral ammonium neurotransmitters. The enantioselectivity reached with these new enantiopure cages is unprecedented for a receptor with 3-fold symmetry as well as the selectivity change observed for a given substrate with enantiomeric receptors. A nanomechanical process from an imploded to a reinflated form upon protonation/deprotonation was demonstrated. This motion occurs both with the host alone and with the host-guest complex, which allows simple control of the uptake and release of the enantiopure neurotransmitter.
(1) (a) Moberg, C. Can $C_{3}$-Symmetric Receptors Differentiate Enantiomers? Angew. Chem., Int. Ed. 2006, 45, 4721-4723. (b) Moberg, C. $C_{3}$ Symmetry in Asymmetric Catalysis and Chiral Recognition. Angew. Chem., Int. Ed. 1998, 37, 248-268. (c) Moberg, C. The Role of Symmetry in Asymmetric Catalysis. Isr. J. Chem. 2012, $52,653-662$.

(2) (a) Loeb, A. L. Color and Symmetry; Wiley: New York, 1971. (b) Rosen, J. Symmetry Discovered; Cambridge University Press: Cambridge, 1975. (c) Lockwood, E. H.; Macmillan, R. H. Geometric Symmetry; Cambridge University Press: Cambridge, 1978. (d) Mainzer, K. Symmetrien der Natur. Ein Handbuch der Natur- und Wissenschaftsphilosophie; DeGruyter: Berlin, 1988. (e) Escher, M. C. Visions of Symmetry; Freeman: New York, 1990. (f) Heilbronner, E.; Dunitz, J. D. Reflections on Symmetry in Chemistry... and Elsewhere; Verlag Helvetica Chimica Acta and VCH: Basel and Weinheim, 1993.

(3) Eliel, E. L.; Wilen, S. H. Stereochemistry of Organic Compounds; John Wiley \& Sons, 1994.

(4) Kagan, H. B.; Dang, T. P. Asymmetric catalytic reduction with transition metal complexes. I. Catalytic system of rhodium(I) with (-)-2,3-0-isopropylidene-2,3-dihydroxy-1,4-bis(diphenylphos- 
phino)-butane, a new chiral diphosphine. J. Am. Chem. Soc. 1972, 94, 6429-6433.

(5) (a) Yoon, T. P.; Jacobsen, E. N. Privileged chiral catalysts. Science 2003, 299, 1691-1693. (b) Zhou, Q.-L. Privileged Chiral Ligands and Catalysts; Wiley-VCH: Weinheim, 2011.

(6) Wang, B.-Y.; Stojanović, S.; Turner, D. A.; Young, T. L.; Hadad, C. M.; Badjic, J. D. The entrapment of chiral guests with gated baskets: can a kinetic discrimination of enantiomers be governed through gating ? Chem. - Eur. J. 2013, 19, 4767-4775.

(7) Löhr, H.-G.; Vögtle, F. Chromo-and fluoroionophores. A new class of dye reagents. Acc. Chem. Res. 1985, 18, 65-72.

(8) (a) Kim, S.-G.; Kim, K.-H.; Jung, J.; Shin, S. K.; Ahn, K. H. Unprecedented Chiral Molecular Recognition in a $C_{3}$-Symmetric Environment. J. Am. Chem. Soc. 2002, 124, 591-596. (b) Schnopp, M.; Haberhauer, G. Highly Selective Recognition of $\alpha$-Chiral Primary Organoammonium Ions by $\mathrm{C}_{3}$-Symmetric Peptide Receptors. Eur. J. Org. Chem. 2009, 2009, 4458-4467.

(9) (a) Pradhan, T.; Jung, H. S.; Jang, J. H.; Kim, T. W.; Kang, C.; Kim, J. S. Chemical sensing of neurotransmitters. Chem. Soc. Rev. 2014, 43, 4684-4713. (b) You, L.; Zha, D.; Anslyn, E. V. Recent advances in supramolecular analytical chemistry using optical sensing. Chem. Rev. 2015, 115, 7840-7892.

(10) (a) Zhang, D.; Ronson, T. K.; Güryel, S.; Thoburn, J.; Wales, D. J.; Nitschke, J. R. Temperature Controls Guest Uptake and Release from Zn4L4 Tetrahedra. J. Am. Chem. Soc. 2019, 141, 14534-14538.

(b) Zhuang, J.; Gordon, M. R.; Ventura, J.; Li, L.; Thayumanavan, S. Multi-stimuli responsive macromolecules and their assemblies. Chem. Soc. Rev. 2013, 42, 7421-7435. (c) McConnell, A. J.; Aitchison, C. M.; Grommet, A. B.; Nitschke, J. R. Subcomponent exchange transforms an $\mathrm{Fe}_{4}^{\mathrm{II}} \mathrm{L}_{4}$ cage from high- to low-spin, switching guest release in a two-cage system. J. Am. Chem. Soc. 2017, 139, 62946297. (d) Jimenez, A.; Bilbeisi, R. A.; Ronson, T. K.; Zarra, S.; Woodhead, C.; Nitschke, J. R. Selective encapsulation and sequential release of guests within a self-sorting mixture of three tetrahedral cages. Angew. Chem., Int. Ed. 2014, 53, 4556-4560. (e) Zhiquan, L.; Xie, H.; Border, S. E.; Gallucci, J.; Pavlovic, R. Z.; Badjic, J. D. A Stimuli-Responsive Molecular Capsule with Switchable Dynamics, Chirality, and Encapsulation Characteristics. J. Am. Chem. Soc. 2018, 140, 11091-11100. (f) Wang, X. Q.; Li, W.-J.; Wang, W.; Wen, J.; Zhang, Y.; Tan, H.; Yang, H.-B. Construction of type iii-c rotaxanebranched dendrimers and their anion-induced dimension modulation feature. J. Am. Chem. Soc. 2019, 141, 13923-13930. (g) DiazMoscoso, A.; Ballester, P. Light-responsive molecular containers. Chem. Commun. 2017, 53, 4635-4652. (h) Dube, H.; Ajami, D.; Rebek, J., Jr. Photochemical control of reversible encapsulation. Angew. Chem., Int. Ed. 2010, 49, 3192-3195. (i) Han, M.; Michel, R.; He, B.; Chen, Y. S.; Stalke, D.; John, M.; Clever, G. H. Light-triggered guest uptake and release by a photochromic coordination cage. Angew. Chem., Int. Ed. 2013, 52, 1319-1323. (j) Preston, D.; Fox-Charles, A.; Lo, W. K.; Crowley, J. D. Chloride triggered reversible switching from a metallosupramolecular $\left[\mathrm{Pd}_{2} \mathrm{~L}_{4}\right]^{4+}$ cage to a $\left[\mathrm{Pd}_{2} \mathrm{~L}_{2} \mathrm{C}_{1} 4\right]$ metallomacrocycle with release of endo- and exo-hedrally bound guests. Chem. Commun. 2015, 51, 9042-9045. (k) Samanta, S. K.; Quigley, J.; Vinciguerra, B.; Briken, V.; Isaacs, L. Cucurbit[7]uril Enables Multi-stimuli-responsive release from the self-assembled hydrophobic phase of a metal organic polyhedron. J. Am. Chem. Soc. 2017, 139, 9066-9074. (1) Kim, T. Y.; Vasdev, R. A. S.; Preston, D.; Crowley, J. D. Strategies for reversible guest uptake and release from metallosupramolecular architectures. Chem. - Eur. J. 2018, 24, 1487814890 .

(11) Lefevre, S.; Zhang, D.; Godart, E.; Jean, M.; Vanthuyne, N.; Mulatier, J.-C.; Dutasta, J.-P.; Guy, L.; Martinez, A. Large-Scale Synthesis of Enantiopure Molecular Cages: Chiroptical and Recognition Properties. Chem. - Eur. J. 2016, 22, 2068-2074.

(12) Hardie, M. J. Recent Advances in the Chemistry of Cyclotriveratrylene. Chem. Soc. Rev. 2010, 39, 516-527.

(13) Xie, X.; Ding, L.; Ni, G.; Zhang, Z.; Gao, J. A General and Facile Approach for the Synthesis of $2^{\prime}$-Functionalized 1,1'-Binapthyl2-ols. Chin. J. Chem. 2010, 28, 1630-1634.
(14) Zhang, D.; Martinez, A.; Dutasta, J.-P. Emergence of Hemicryptophanes: From Synthesis to Applications for Recognition, Molecular Machines, and Supramolecular Catalysis. Chem. Rev. 2017, 117, 4900-4942.

(15) Zhang, D.; Cochrane, J. R.; Di Pietro, S.; Guy, L.; Gornitzka, H.; Dutasta, J.-P.; Martinez, A. Breathing" Motion of a Modulable Molecular Cavity. Chem. - Eur. J. 2017, 23, 6495-6498.

(16) (a) Zimenkov, Y.; Dublin, S. N.; Ni, R.; Tu, R. S.; Breedveld, V.; Apkarian, R. P.; Conticello, V. P. Rational design of a reversible $\mathrm{pH}$-responsive switch for peptide self-assembly. J. Am. Chem. Soc. 2006, 128, 6770-6771. (b) Nakabayashi, K.; Kawano, M.; Fujita, M. $\mathrm{pH}$-Switchable Through-Space Interaction of Organic Radicals within a Self-Assembled Coordination Cage. Angew. Chem., Int. Ed. 2005, 44, 5322-5325. (c) McConnell, A. J.; Wood, C. S.; Neelakandan, P. P.; Nitschke, J. R. Stimuli-responsive metal-ligand assemblies. Chem. Rev. 2015, 115, 7729-7793. (d) Cullen, W.; Turega, S.; Hunter, C. A.; Ward, M. D. pHdependent binding of guests in the cavity of a polyhedral coordination cage: reversible uptake and release of drug molecules. Chem. Sci. 2015, 6, 625-631.

(17) Steed, J. W.; Atwood, J. L. J. L. Atwood Supramolecular Chemistry; Wiley-Blackwell, 2009.

(18) Hibbert, D. B.; Thordarson, P. The death of the Job plot, transparency, open science and online tools, uncertainty estimation methods and other developments in supramolecular chemistry data analysis. Chem. Commun. 2016, 52, 12792-12805. 